\title{
Using fruitflies to help understand the molecular mechanisms of human hereditary diffuse gastric cancer
}

\author{
JOANA CALDEIRA ${ }^{1,4}$, PAULO S. PEREIRA ${ }^{2,3}$, GIANPAOLO SURIANO ${ }^{4}$ and FERNANDO CASARES ${ }^{*}, 1,2$ \\ ${ }^{1}$ Centro Andaluz de Biología del Desarrollo (CABD), CSIC-Universidad Pablo de Olavide, Sevilla, Spain, \\ 2IBMC, Universidade do Porto, Porto, Portugal, ${ }^{3}$ School of Health Sciences, University of Minho, Braga, Portugal and \\ ${ }^{4}$ IPATIMUP, Universidade do Porto, Porto, Portugal.
}

\begin{abstract}
Mutations in the $C D H 1$ gene, which encodes the cell adhesion molecule E-cadherin, are associated with hereditary diffuse gastric cancer in humans. Although most of the CDH1 mutations found are truncating, leading to non-functional E-cadherin, some are missense. These missense E-cadherin mutants result in full-length proteins which, when assayed in cell culture, still retain some biological activity. In order to understand the molecular causes of the malfunction of the E-cadherin missense forms found in patients, we developed a Drosophila model, where the effects of expressing the mutant forms can be studied in vivo (Pereira et al., 2006). Here, we review the results obtained so far, and outline possible ways of exploiting the fly model system to screen for pathways affected by specific E-cadherin missense mutant forms and to identify mechanisms that contribute to tumourigenesis.
\end{abstract}

KEY WORDS: gastric cancer, E-cadherin, $\beta$-catenin, adhesion, Drosophila

\section{Introduction}

Gastric Cancer (GC), as most of human cancers ( 80-90\%), originates from epithelial cells (Christofori and Semb, 1999). Although the incidence rate of this type of cancer has significantly decreased during the last century, it is still responsible for more than half a million deaths per year, ranking second in terms of global cancer burden worldwide (Caldas etal., 1999, Dunbier and Guilford, 2001).

As much as $90 \%$ of gastric cancer cases arise in a sporadic setting, whereas for the remaining $10 \%$ familial clustering is observed (Zanghieri et al., 1990; La Vecchia et al., 1992). Both familial and sporadic gastric cancers are products of multiple genetic and epigenetic alterations that transform normal gastric epithelial cells into malignant neoplasms. These include activation of oncogenes through mutation and/or amplification, or biallelic inactivation of tumour suppressor genes through mutation and loss of heterozygosity ( $\mathrm{LOH}$ ) or promoter hypermethylation. (Berx et al., 1998, Carneiro et al., 2004, Christofori and Semb, 1999, Dunbier and Guilford, 2001, Fitzgerald and Caldas, 2004, Hirohashi, 1998, Moran et al., 2005, Oliveira et al., 2006). Hereditary diffuse gastric cancer (HDGC) is an autosomal, dominant inherited gastric cancer susceptibility syndrome, which account for $1-3 \%$ of all gastric cancer cases (Ford, 2002). In 1998, germline truncating mutations in the E-cadherin (Ecad) gene were described in three Maori families with predisposition to diffuse gastric cancer (Elterman et al., 2001). Similar mutations have been since described in close to 60 other families of different ethnic backgrounds (Suriano et al., 2006). All these mutations result in dysfunctions in E-cadherin, a molecule found at intercellular junctions and that links epithelial cells by establishing both homophilic and heterophilic, calcium-dependent, interactions across the intercellular space (Chappuis-Flament et al., 2001, Oliveira et al., 2006, Panorchan et al., 2006, Steinberg and McNutt, 1999).

$C D H 1$ germ-line inactivating mutations have a disease-penetrance in the range of $70 \%$ to $80 \%$. Usually diffuse gastric cancers become symptomatic only when they are already incurable (Caldas et al., 1999, Fitzgerald and Caldas, 2004, Lynch et al., 2005).

The most obvious characteristic of diffuse-type cancers is the

\footnotetext{
Abbreviations used in this paper: $\mathrm{CDH} 1$, cadherin 1/ type 1 E-cadherin; Ecadherin, epithelial cadherin; LOH, loss of heterozygosity; HDGC, hereditary diffuse gastric cancer; DEcad, Drosophila epithelial cadherin; $\mathrm{CHO}$, Chinese hamster ovary; Shg, shotgun; hEcad, human epithelial cadherin; UAS, upstream activating sequence; $\mathrm{AJs}$, adherensjunctions; GFP, green fluorescent protein; MARCM, mosaic analysis with a repressible cell marker.
}

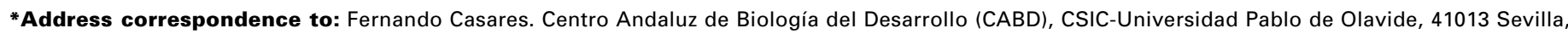
Spain. Fax: +34-954-349-376. e-mail: fcasfer@upo.es web: http://www.cabd.es/en-research_groups.htm।

Final author-corrected PDF published online: 26 November 2008.

ISSN: Online 1696-3547, Print 0214-6282

(c) 2009 UBC Press

Printed in Spain 
complete loss of cell-cell adhesiveness, resulting in destruction of the histological structure, followed by a strong tendency to invade, the morphological hallmark of malignant tumours. Invasion and metastasis only occur at later stages of the disease (Christofori and Semb, 1999, Hirohashi, 1998). Focal dissociation or dedifferentiation are characteristics of the leading invasive cells of solid tumours with a great ability to metastasize (Hirohashi, 1998).

In an attempt to classify the numerous subgroups of gastric tumours, many different classification systems have been formulated, taking into account parameters such as biological behaviour and prognostic indicators. Yet, there is agreement on one thing: the downregulation of E-cadherin correlates with the shift from well-differentiated adenoma to invasive carcinoma, and it is a necessary event in the progression of epithelial tumours (Christofori and Semb, 1999, Dunbier and Guilford, 2001, El-Rifai and Powell, 2002, Guilford, 1999).

E-cadherin dysfunctions in HDGC are a result, in many instances, of inactivating mutations in its coding gene $C D H 1$ (such as nonsense and frameshift mutations or those affecting splice sites) that result in an inactive molecule (Fitzgerald and Caldas, 2004). However, missense mutations have also been found in HDGC patients. These mutations in $C D H 1$, which cause the substitution of one aminoacid and still give rise to normal length molecules, are a clinical burden still out on debate, since their biological consequences are unknown (Oliveira et al., 2006).

Missense mutations are also some kind of a paradox: they retain some biological function when assayed in cell cultures, but still are associated with HDGC and, therefore, should behave as null proteins (at least in early stages of the tumour). Nevertheless, the gap between cell culture studies and the situation found in vivo, in a tissue context, is huge. In addition, each missense mutation affects different domains of the E-cadherin molecule, which might result in significant differences in E-cadherin's ability to interact (or fail to interact) with molecular partners and signalling pathways, or even in anomalous subcellular localizations (Chen et al., 1999).

\section{Results}

\section{Drosophila to understand the molecular mechanism affected} by E-cadherin missense mutations in gastric cancer

To understand what specific consequences each missense mutation has in a tissue and to use this knowledge in helping the prognosis of their associated malignancies, our aim was to generate a simple in vivomodel in which we would be able to study cellular, genetic and molecular modifications associated with HDGC in a tissue context, to overcome all the technical problems inherent to cell cultures and with a sufficiently large "tool kit" to address these points in a time and cost-efficient manner.

The model of choice was Drosophila melanogaster. The junc- tional complexes along the epithelial cell membrane and overall epithelial organization are sufficiently similar in invertebrates and vertebrates to assume that most cellular and molecular mechanisms involved in epithelial maintenance and reorganization are conserved (Fig. 1).

For instance, during Drosophilagastrulation, the loss of epithelial junctions by degradation of DE-cadherin (DEcad) causes cells to go through what looks like a typical vertebrate epithelialmesenchymal transition (Locascio and Nieto, 2001, Oda et al., 1998).

The pipeline in the construction of a Drosophila model for the study of the molecular consequences of different forms of missense human E-cadherin (hEcad) included the ability to direct their expression in Drosophila epithelia and to check for a normal (or almost) pattern of subcellular localization. Also, the functional interactions of overexpressed hEcad could be determined by genetic means. Then, each missense form should be interrogated, by the same genetic tests, about abnormal functional interactions when compared with the wild type hEcad form. This comparison should yield candidate genetic pathways affected by all mutations or specific for particular mutations, being those pathways good candidates to be explored in other systems as likely affected downstream of the mutant hEcads in cancer.

In addition, Drosophilacan also add to our understanding of the initiating events in cancers where the loss of Ecad is causative. In order to generate the Drosophila model and to follow up the Drosophila work with experiments in other systems, two groups from Porto University (F. Casares at IBMC and R. Seruca/G. Suriano at IPATIMUP) joint efforts in 2002. The IPATIMUP group had been involved in the discovery of the association of $C D H 1$ mutations to HDGC, and was at the time in the process of identifying new $C D H 1$ mutations in HDGC patients and character- 
izing the missense mutant forms in $\mathrm{CHO}$ cell culture assays (Suriano et al., 2003a, Suriano et al., 2003b, Suriano et al., 2005) The IBMC group chipped in with their expertise in Drosophila genetic manipulation and developmental biology.

To express hEcad forms in Drosophila we used the binary system GAL4/UAS (Brand and Perrimon, 1993, Phelps and Brand, 1998). In this system, a GAL4-driver line, in which the transactivator GAL4 is expressed in a specific tissue pattern, is crossed to a responder-UAS line. The responder harbours a transgene in which the cDNA of interest (in our case the Ecads) is cloned downstream of the UAS sequences, to which GAL4 binds. In the progeny, Ecads expression will be targeted to the GAL4-expressing territories. For our experiments, wild type hEcad and the missense mutants (V832M and A634V) were cloned under UAS and stable transgenic lines established for each of them. The target tissues were the imaginal discs, formed by a simple, monoloayered epithelium, which give rise to adult external structures of the adult fly, such as wings or eyes (Cohen, 1993), and that can be easily dissected form larvae (Fig. 1).

Expression of hEcad in developing Drosophila epithelia resulted in its targeting to the apical cell membrane, where the endogenous DEcad is involved in forming the adherens junctions (AJs). Increasing the levels of expression by raising the culture temperature (as the Gal4/UAS system is temperature sensitive), leads to accumulation of hEcad in more basal localizations of the membrane, likely due to overexpression. In these situations, ectopic actin foci are formed that correlate with an increased membrane Armadillo accumulation - the fly $\beta$-catenin homologue. This result indicated that, even if the human Ecad protein is not completely homologous to the endogenous DEcad (Fig. 2), the human form reaches the right membrane domains and, also, that it interacts with expected molecular partners, in this case $\beta$ catenin, capable of triggering actin cytoskeleton assembly (Bienz, 2005, Nelson and Nusse, 2004, Pereira et al., 2006, Wheelock and Johnson, 2003).

Two other observations were of interest: if hEcad is driven in cells ubiquitously expressing GFP-tagged DEcad, the amounts of GFP-DEcad decrease, indicating that DEcad is subject to a posttranslational downregulation upon hECad overexpression. Also, confocal microscopy analysis showed that most foci of Ecad staining contained either hEcad or DEcad, suggesting that different Ecads segregate into different junctional complexes, maybe due to a preference in engaging in strictly homotypic interactions. The subcellular localization of overexpressed missense mutant variants $\mathrm{A} 634 \mathrm{~V}$ and $\mathrm{V} 832 \mathrm{M}$, at our level of resolution, was similar to that of the wild type hECad. Nevertheless, another mutation affecting the extracellular domain, T340A, was not produced at high levels and was never detected on the cell membrane, although it could be localized correctly in $\mathrm{CHO}$ transfected cells. This mutation might be affecting the stability of the protein or its intracellular transport. Whether this defect is specific of the Drosophila cells, or can also happen in human tissues is not known. If the latter were the case, the abnormal production of EcadT340A could result in this variant behaving as a null product.

In imaginal discs, daughter cells do not migrate away from one another, and cell groups normally do not suffer major rearrangements. Using this property, we checked the migratory/invasive behaviour of Drosophila disc cells when missense forms of hEcad were expressed in solid domains. The initial hypothesis was that each of the missense forms might mimic in vivo(in Drosophila) the behaviour they exhibited when transfected in $\mathrm{CHO}$ cells (Suriano et al., 2003b), especially since the overexpressed hECad becomes the major species in the AJs of overexpressing cells. When expressed in solid domains in the discs, cells expressing wild type hEcad remained together. This was not the case, though, when the A634V and V832M forms were expressed: expressing cells intermingled with non-expressing ones. Even more, while $\mathrm{A} 634 \mathrm{~V}^{+}$ cells migrated in groups, V832M+ did so as small clusters or even as isolated cells, and were able to basally exit the epithelium. These results reproduced in the Drosophila system the cellular behaviour elicited upon transfection of these specific mutant forms in cell culture. Also, it allowed the phenotypic discrimination of at least three forms, one wild type and two mutants of hECad.

Interestingly, the V832M form, which harbours a mutation close to the $\beta$-catenin interaction domain, showed a weaker molecular interaction with the endogenous homologue, Armadillo. When the adult derivatives of these hEcad-expressing tissues were further examined, we realized that the phenotypes were also distinct, likely due to the different abilities of each of the forms to interact with the Wnt signalling pathway through their differential interaction with Armadillo. This protein holds a dual cellular role: to be bound to Ecad at the junctions and to act as nuclear transducer of the Wnt signalling pathway (Bienz, 2005). The further phenotypic analysis also revealed a putative interaction with a key signalling pathway also involved in cancer, that of Notch. Considered together, these results indicated that using the Drosophilasystem it was possible to gather information regarding cellular and molecular effects of the human Ecad variants, and that the system was sensitive enough as to discriminate phenotypically different mutations.

\section{Perspectives}

Several questions related to HDGC lay ahead that could also be tackled using Drosophila. One of them is still surprisingly unexplored: the loss of Ecad function as the initiating effect in tumourigenesis. On the one hand, cell lines lacking Ecad exist, but these are also immortalized and, therefore, must carry other alterations that mask the cell behaviour of a cell that just lacks Ecad. On the other, one might predict that the sole loss of Ecad should result in loss of cell-cell contact and anoikis, so either
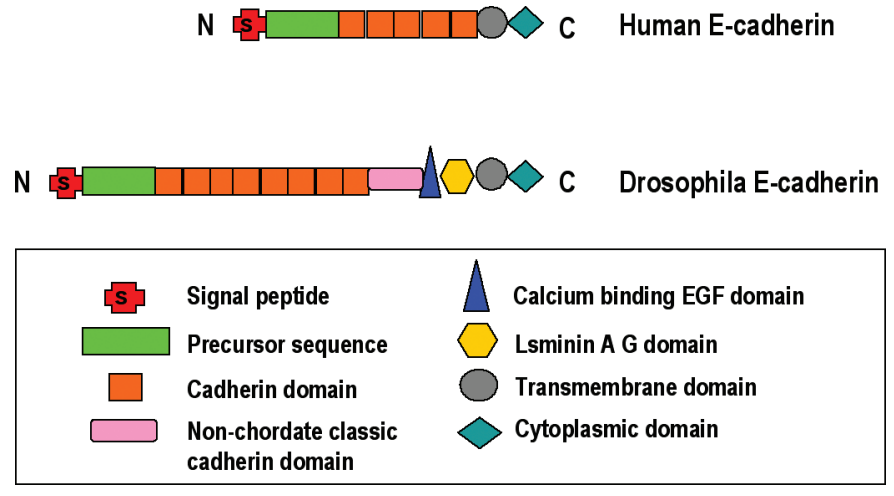

Fig. 2. Comparison of the domain structures of human and Drosophila E-cadherin. 
gastric cells are particularly resilient to Ecad loss, or some coadjuvant alterations should cooperate with the loss of Ecad to send a gastric cell down the tumoural road. In any case, these "coadjuvants", either gastric-specific or mutation-induced, are not fully understood. Some candidates are emerging, such as the tumour suppressor Scribble, which in mammalian cell cultures mediates $E$-cadherin adhesion and stabilizes alpha and $\beta$-catenin in the cell. (Qin et al., 2005). In Drosophila it is possible to study the initiating event in a tissue context by inducing clones of marked cells mutant for the DEcad-coding gene, shotgun (shg), and following their behaviour. Even more, using the MARCM technique (Lee and Luo, 2001), it is possible to express specifically in the mutant shg cells other gene products to activate or repress specific signalling pathways, to then ask to what extent these pathways are able to promote tumour-like behaviour of DEcad cells. If the tested pathway contributes to the tumour-like behaviour, then it is possible to use the system to further analyze the cellular mechanisms through which it does so (such as apoptosis resistance, epithelial extrusion, cell migration etc.).

Another aim is to uncover why the missense proteins, although retaining some - and importantly, allele-specific - biological activity in cell culture, seem to be conducive to cancer. One possibility is that these mutations have some dominant effect. This seems unlikely, though, because carriers do not seem to develop the disease unless the wild type loci become also inactivated. Thus, the most likely possibility is that the mutations affect the interactions of Ecad with critical pathways, even if retaining some of the wild-type functions. To uncover these interactions, it is possible to devise genetic screenings. For example, the overexpression of different hEcad forms, wild type and missense mutants, produce distinctive roughening of the fruitfly eye, indicating that their effects differ quantitatively and/or qualitatively. These overexpression genotypes can be then crossed into different genetic backgrounds, and those able to modify (enhance or suppress) the phenotype, be selected as candidate interactors. Importantly, it is expected that mutant forms lack some specific interaction shown by the wild type hEcad, and that these missing (or altered) interactions would play a role in tumour formation.

As Garth Nicolson put it (Nicolson, 2004), and we can ratify from our own experience, the way to approach and treat various diseases is changing because of the necessity for an increasing "integration of areas previously somewhat segregated", especially when studying diseases as complex and multifarious as cancer.

\section{Acknwoledgements}

Work reviewed here has been funded through grants POCTI/CBO/ 44770/2002 and POCI/SAU-OBS/57111/2004 from Fundação para a Ciência e a Tecnologia (Portugal), co-funded by FEDER.

\section{References}

BERX, G., BECKER, K.F., HOFLER, H. and VAN ROY, F. (1998). Mutations of the human E-cadherin (cdh1) gene. Hum. Mutat. 12: 226-237.

BIENZ, M. (2005). Beta-catenin: A pivot between cell adhesion and Wnt signalling. Curr. Biol. 15: R64-67.

BRAND, A.H. and PERRIMON, N. (1993). Targeted gene expression as a means of altering cell fates and generating dominant phenotypes. Development 118 : 401-415.
CALDAS, C., CARNEIRO, F., LYNCH, H.T., YOKOTA, J., WIESNER, G.L., POWELL, S.M., LEWIS, F.R., HUNTSMAN, D.G., PHAROAH, P.D., JANKOWSKI, J.A. et al. (1999). Familial gastric cancer: Overview and guidelines for management. J. Med. Genet. 36: 873-880.

CARNEIRO, F., HUNTSMAN, D.G., SMYRK, T.C., OWEN, D.A., SERUCA, R., PHAROAH, P., CALDAS, C. and SOBRINHO-SIMOES, M. (2004). Model of the early development of diffuse gastric cancer in $\mathrm{E}$-cadherin mutation carriers and its implications for patient screening. J. Pathol. 203: 681-687.

CHAPPUIS-FLAMENT, S., WONG, E., HICKS, L.D., KAY, C.M. and GUMBINER, B.M. (2001). Multiple cadherin extracellular repeats mediate homophilic binding and adhesion. J. Cell Biol. 154: 231-243.

CHEN, Y.T., STEWART, D.B. and NELSON, W.J. (1999). Coupling assembly of the $\mathrm{E}$-cadherin/beta-catenin complex to efficient endoplasmic reticulum exit and basal-lateral membrane targeting of E-cadherin in polarized MDCK cells. J. Cell Biol. 144: 687-699.

CHRISTOFORI, G. and SEMB, H. (1999). The role of the cell-adhesion molecule E-cadherin as a tumour-suppressor gene. Trends Biochem. Sci. 24: 73-76.

COHEN, S.M. (1993). Imaginal Disc Development. In: The Development of Drosophila melanogaster (A. Martínez Arias, Ed.), Vol. 2, pp. 747-841. Cold Spring Harbor Laboratory Press, Cold Spring Harbor, NY.

DUNBIER, A. and GUILFORD, P. (2001). Hereditary Diffuse Gastric Cancer. AdV. Cancer Res. 83: 55-65.

EL-RIFAI, W. and POWELL, S.M. (2002). Molecular biology of gastric cancer. Semin. Radiat. Oncol. 12: 128-140.

ELTERMAN, D., WARBY, S. and COBURN, B.A. (2001). Digesting genetic information in gastric cancers. Clin. Genet. 60: 264-265.

FITZGERALD, R.C. and CALDAS, C. (2004). Clinical implications of E-cadherin associated Hereditary Diffuse Gastric Cancer. Gut53: 775-778.

FORD, J.M. (2002). Inherited susceptibility to gastric cancer advances in genetics and guidelines for clinical management. In: American Society of Clinical Oncology 2002 Educational Book (M. C. Perry, Ed), pp. 116-125.

GUILFORD, P. (1999). E-cadherin downregulation in cancer: Fuel on the fire? Mol. Med. Today 5: 172-177.

HIROHASHI, S. (1998). Inactivation of the E-cadherin-mediated cell adhesion system in human cancers. Am. J. Pathol. 153: 333-339.

LA VECCHIA, C., NEGRI, E., FRANCESCHI, S. and GENTILE, A. (1992). Family history and the risk of stomach and colorectal cancer. Cancer70: 50-55.

LEE, T. and LUO, L. (2001). Mosaic analysis with a repressible cell marker (MARCM) for Drosophila neural development. Trends Neurosci. 24: 251-254.

LOCASCIO, A. and NIETO, M.A. (2001). Cell movements during vertebrate development: Integrated tissue behaviour versus individual cell migration. Curr. Opin. Genet. Dev. 11: 464-469.

LYNCH, H.T., GRADY, W., SURIANO, G. and HUNTSMAN, D. (2005). Gastric cancer: New genetic developments. J. Surg. Oncol. 90: 114-133; discussion 133.

MORAN, C.J., JOYCE, M. and MCANENA, O.J. (2005). Cdh1 associated gastric cancer: A report of a family and review of the literature. Eur. J. Surg. Oncol. 31: 259-264.

NELSON, W.J. and NUSSE, R. (2004). Convergence of Wnt, beta-catenin, and cadherin pathways. Science 303: 1483-1487.

NICOLSON, G. (2004). Molecular cell biology and cancer metastasis. An interview with Garth Nicolson. Int. J. Dev. Biol. 48: 355-363.

ODA, H., TSUKITA, S. and TAKEICHI, M. (1998). Dynamic behaviour of the cadherin-based cell-cell adhesion system during Drosophila gastrulation. Dev Biol. 203: 435-450.

OLIVEIRA, C., SERUCA, R. and CARNEIRO, F. (2006). Genetics, pathology, and clinics of familial gastric cancer. Int. J. Surg. Pathol. 14: 21-33.

PANORCHAN, P., THOMPSON, M.S., DAVIS, K.J., TSENG, Y., KONSTANTOPOULOS, K. and WIRTZ, D. (2006). Single-molecule analysis of cadherin-mediated cell-cell adhesion. J. Cell Sci. 119: 66-74.

PEREIRA, P.S., TEIXEIRA, A., PINHO, S., FERREIRA, P., FERNANDES, J., OLIVEIRA, C., SERUCA, R., SURIANO, G. and CASARES, F. (2006). Ecadherin missense mutations, associated with Hereditary Diffuse Gastric Cancer (HDGC) syndrome, display distinct invasive behaviours and genetic interactions with the Wnt and Notch pathways in Drosophila epithelia. Hum. Mol. 
Genet. 15: 1704-1712.

PHELPS, C.B. and BRAND, A.H. (1998). Ectopic gene expression in Drosophila using gal4 system. Methods 14: 367-379.

QIN, Y., CAPALDO, C., GUMBINER, B.M. and MACARA, I.G. (2005). The mammalian scribble polarity protein regulates epithelial cell adhesion and migration through E-cadherin. J. Cell Biol. 171: 1061-1071.

STEINBERG, M.S. and MCNUTT, P.M. (1999). Cadherins and their connections: Adhesion junctions have broader functions. Curr. Opin. Cel/ Biol. 11: 554-560.

SURIANO, G., MULHOLLAND, D., DE WEVER, O., FERREIRA, P., MATEUS, A.R., BRUYNEEL, E., NELSON, C.C., MAREEL, M.M., YOKOTA, J., HUNTSMAN, D. et al. (2003a). The intracellular E-cadherin germline mutation V832M lacks the ability to mediate cell-cell adhesion and to suppress invasion. Oncogene 22: $5716-5719$

SURIANO, G., OLIVEIRA, M.J., HUNTSMAN, D., MATEUS, A.R., FERREIRA, P.,
CASARES, F., OLIVEIRA, C., CARNEIRO, F., MACHADO, J.C., MAREEL, M. et al. (2003b). E-cadherin germline missense mutations and cell phenotype: Evidence for the independence of cell invasion on the motile capabilities of the cells. Hum. Mol. Genet. 12: 3007-3016.

SURIANO, G., YEW, S., FERREIRA, P., SENZ, J., KAURAH, P., FORD, J.M., LONGACRE, T.A., NORTON, J.A., CHUN, N., YOUNG, S. et al. (2005). Characterization of a recurrent germ line mutation of the $\mathrm{E}$-cadherin gene: Implications for genetic testing and clinical management. Clin. Cancer Res. 11: 5401-5409.

WHEELOCK, M.J. and JOHNSON, K.R. (2003). Cadherin-mediated cellular signalling. Curr. Opin. Cell Biol. 15: 509-514.

ZANGHIERI, G., DI GREGORIO, C., SACCHETTI, C., FANTE, R., SASSATELLI, R., CANNIZZO, G., CARRIERO, A. AND PONZ DE LEON, M. (1990). Familial occurrence of gastric cancer in the 2-year experience of a population-based registry. Cancer66, 2047-2051.

\section{Related, previously published Int. J. Dev. Biol. articles}

See our recent Special Issue Ear Development edited by Fernando Giraldez and Bernd Fritzsch at:

http://www.ijdb.ehu.es/web/contents.php?vol=51\&issue=6-7

Expression of protocadherin 18 in the CNS and pharyngeal arches of zebrafish embryos

Fumitaka Kubota, Tohru Murakami, Yuki Tajika and Hiroshi Yorifuji

Int. J. Dev. Biol. (2008) 52: 2424-2424

The expression of Fat-1 cadherin during chick limb development Terence G. Smith, Nick Van Hateren, Cheryll Tickle and Stuart A. Wilson Int. J. Dev. Biol. (2007) 51: 173-176

Cadherin- 6 is required for zebrafish nephrogenesis during early development Fumitaka Kubota, Tohru Murakami, Kenji Mogi and Hiroshi Yorifuji Int. J. Dev. Biol. (2007) 51: 123-129

$\mathrm{N}$-cadherin in the spotlight of cell-cell adhesion, differentiation, embryogenesis, invasion and signalling

Lara D.M. Derycke and Marc E. Bracke

Int. J. Dev. Biol. (2004) 48: 463-476

Cadherin-mediated cell-cell adhesion and tissue segregation in relation to malignancy

Ramsey A. Foty and Malcolm S. Steinberg

Int. J. Dev. Biol. (2004) 48: 397-409

Discovery and characterization of the cadherin family of cell adhesion molecules. An interview with Masatoshi Takeichi

Douglas Sipp

Int. J. Dev. Biol. (2004) 48: 387-396

Transcriptional regulation of cadherins during development and carcinogenesis Héctor Peinado, Francisco Portillo and Amparo Cano

Int. J. Dev. Biol. (2004) 48: 365-375

Germinal tumor invasion and the role of the testicular stroma

Alejandro Díez-Torre, Unai Silván, Olivier De Wever, Erik Bruyneel, Marc Mareel

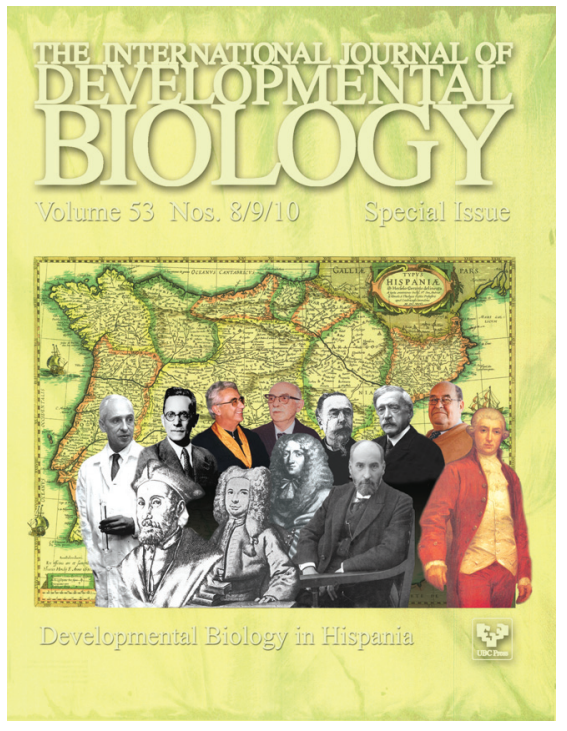

5 yr ISI Impact Factor $(2008)=3.271$

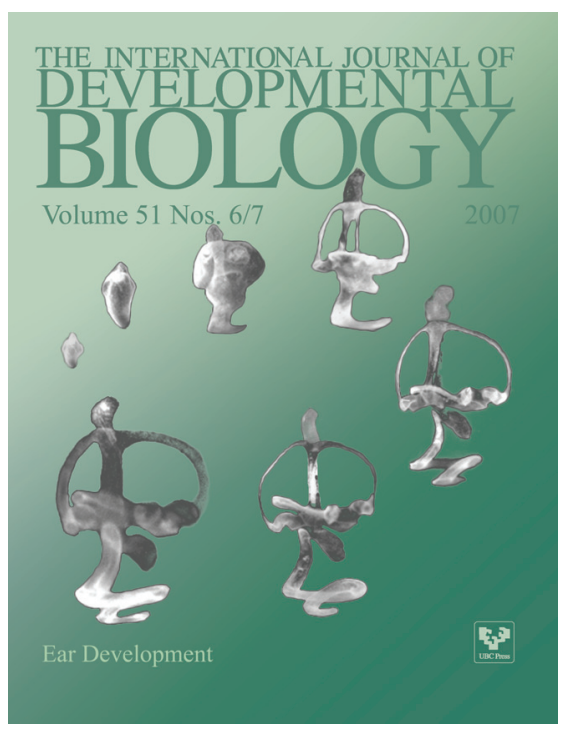

